\title{
In vitro Cultivation of Newly Reported Wild Edible Mushroom Volvariella bomybycina from Nepal
}

Pradip Kumar Chaudhary1,2*, Mitesh Shrestha1, 2, Bal Hari Poudel1, Mahesh Kumar Adhikari1,3

${ }^{1}$ Central Department of Biotechnology, Tribhuvan University, Nepal

${ }^{2} \mathrm{Nepal}$ Academy of Science and Technology, Khumaltar, Nepal

${ }^{3}$ National Herbarium \& Plant Laboratories, Department of Plant Resources, Ministry of Forests and Soil

Conservation, Nepal

\begin{abstract}
Wild edible mushrooms are becoming endangered all over the world. Very few wild edible mushrooms are found in natural habitat. Volvariella bombycina is an edible and medicinal mushroom. The mushroom was collected in natural habitat growing on Populus tree. Mycelium of the mushroom was developed in PDA slant tubes by tissue culture method, incubated at $25^{\circ} \mathrm{C}$ for $1-2$ weeks. Spawn was developed in wheat grains after incubation at $25^{\circ} \mathrm{C}$ for $2-3$ weeks. Substrates were formulated for the development of fruiting bodies by combination of paddy straw, saw dust and rice husk. Fruiting bodies of $V$. bombycina was cultivated in these substrates after incubation at $28 \pm 2{ }^{\circ} \mathrm{C}$ for $2-4$ weeks. The work describes the optimized process for in vitro culture of wild edible mushroom Volvariella bomybycina.
\end{abstract}

Key words: Mushroom; Wild; Edible; cultivation; Volvariella bombycina

*Corresponding author

Email: pradipkchaudhary@biotechtu.edu.np

\section{Introduction}

Wild edible mushrooms possessing medicinal and nutritional properties have been collected and consumed by people since time immemorial [1]. Nepal is rich in biodiversity due to its complex variation in geomorphology and phytogeography [topology, climate and altitudinal]. It is known for being rich in mushroom diversity [2]. Due to this, the exploration for novel mushrooms is of paramount importance. Among such, one important edible and medicinal mushroom, Volvariella bombycina has just been recorded in 2016 by Adhikari M.K on Populus tree from Tribhuvan University, Kirtipur [6].

Volvariella bombycina [Schaeff.:Fr] Singer, commonly known as Silky agaric, Silky sheath, Silky rosegill, Silver-silk straw mushroom, Tree mushroom grows on Populus tree in Nepal and is distributed in China [3], North America [4], India [5], Nepal [6], Pakistan [7] and Korea [8]. $V$. bombycina is a tropical and subtropical species and belongs to the family Pluteaceae [6]. $V$. bombycina usually grows in a shady place on the rotting wood, leaf debris, rich agricultural soil especially in coffee and palm plantation [9]. It is an edible $[9,10]$ tasty, with a modest and pleasant flavor [11] with potential for commercial cultivation $[13,14]$. The morphology of fruiting bodies of $V$. bombycina are highly variable, suggesting a strategy for adaptation against environmental stresses caused by a range of extrinsic factors [3]. The life cycle, hymenial cell type, cystidia and basidia of $V$. bombycina are similar to that of $V$. volvacea. However, on contrary to $V$. volvacea, it requires slightly lower temperature for mycelial growth and fruiting starts from $26^{\circ} \mathrm{C}$ to $30^{\circ} \mathrm{C}$ [14]. $V$. bombycina produces various bioactive secondary metabolites; ergosta-4,6,8[14],22-tetraene-3-one, ergosterol peroxide, indole-3-carboxaldehyde, indazole [15], and isodeoxyhelicobasidin in liquid culture [16]. The mushroom possesses several biological properties such as antioxidative, antitumor, hypocholesterolemic [17] and antimicrobial properties [18].

Volvariella bombycina has a great commercial value all over the globe since it can be consumed as a substitute for meat because of its high protein content and for its enormous medicinal value [19] . Attempts for its' cultivation have not been reported from Nepal till date with few reported attempted from China [3] and India [19]. This difficulty in cultivation could be attributed to variability in nature of fruiting bodies [3]. Similarly, previous methods were not suitable for commercial cultivation. This research utilized the easily available local substrates such as paddy straw and others to 
induce development of fruiting bodies from wild edible mushroom $V$. bombycina.

\section{Materials and Methods Collection, Identification and Handling of Fruiting bodies}

$V$. bombycina was collected from the trunk of Populus tree found at Tribhuvan University, Kirtipur in paper tissue and cultured on the same day. The collected mushroom was identified by morphological and spore print characteristics. Some specimens were dried under natural light at room temperature for several days. Herbarium was prepared and deposited at National Herbarium \& Plant Laboratories, Godawari, Nepal under Department of Plant Resources [DPR].

\section{Isolation of pure culture of mycelium}

Isolation of pure culture of mycelium was performed by tissue culture method [20]. Sterilized inner part of tissue [mycelia] from Pileus and Stipes were inoculated in sterilized Potato Dextrose Medium [PDA] slant tubes under sterile condition and incubated [BOD incubator, Optics Technology] at $25^{\circ} \mathrm{C}$ for $1-2$ weeks. Pure culture of mycelium was obtained by repeated sub culturing process.

\section{Grain Spawn}

The protocol was followed as developed by Chang and Miles with slight modifications. $5 \mathrm{~kg}$ of wheat grains was washed thoroughly in clean water, soaked for one day and mixed with $7.5 \mathrm{~g}$ of $\mathrm{CaCO}_{3}$. The grain mixture was filled in heat resistant polypropylene bags of cover size $28 \mathrm{x}$ $10 \mathrm{~cm}^{2}$ and their mouths were closed using rubber bands. The bags were sterilized in autoclave at $15 \mathrm{lb} / \mathrm{in}^{2}$ pressure at $121^{\circ} \mathrm{C}$ for 30 45 minutes. Pure culture of mycelium was transferred aseptically to sterilized bags filled with substrate. The bags were finally incubated [BOD incubator, Optics Technology] at $25^{\circ} \mathrm{C}$ for 2- 3 weeks [20].

\section{Bed Preparation and Spawn run}

Good paddy straws were selected and chopped into 3-4 inches; washed thoroughly and soaked in boiling water for 60-90 minutes and allowed to cool after draining excess water. Sterilized rice husk and saw dust was added at concentration of $3-5 \%$ by weight of paddy straws. $60 \times 30 \mathrm{~cm}^{2}$ sterilized polypropylene bags were used for packaging of substrate and spawn. Spawns were inoculated at every $5 \mathrm{~cm}$ layers during packaging of substrate. Thus, prepared bags were incubated at $25^{\circ} \mathrm{C}$ in incubator [BOD incubator, Optics Technology]. The spawn run period was 8-10 days and humidity was maintained at $80-90 \%$. Mouth of the polypropylene bags were opened for 1-2 hours once the spawn run period was over for proper air circulation under sterile condition. The incubation was done till the primordial formation.

\section{Development of Fruiting bodies}

During fruiting bodies development, the mouths of the bags were opened up to 6 hours a day under sterile condition for air circulation. Humidity and temperature were maintained up to $90 \%$ and $28 \pm 2{ }^{\circ} \mathrm{C}$ respectively. The fruiting bodies were harvested at egg stage and then in mature stage.

\section{Results}

Morphology of the mushroom

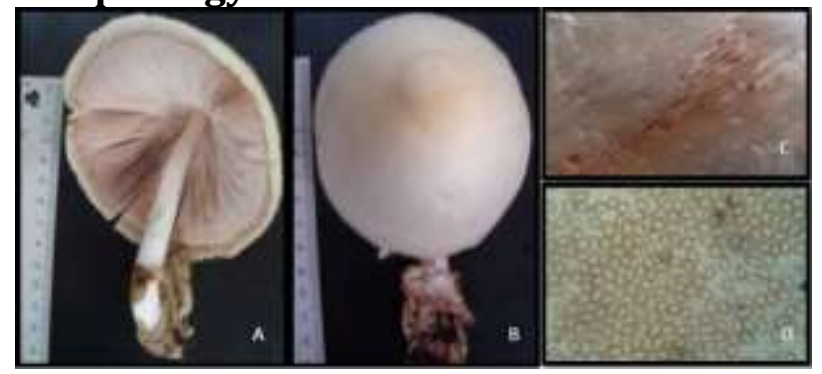

Figure 1: V. bombycina A. Hymenial surface B. Upper surface C. Spore print D. Spores [40X].

$V$. bombycina was observed as large pileus creamy white, dry, and covered with silky hairs measuring $\sim 10 \mathrm{~cm}$ in diameter. Stipe is $13 \mathrm{~cm}$ long and 1-2 $\mathrm{cm}$ thick. The stipe was tapering upwards, cylindrical often curved, dry, white, smooth without a ring. The volva is cup-shaped with irregular margin. It measures $4 \mathrm{~cm}$ long, 2 $\mathrm{cm}$ wide, thick, white to yellowish or brownish, and mouth open sac like. Lamellae are free, at first whitish, later becoming pink, crowded, margin entire Figure $1 \mathbf{A} \& \mathbf{B}]$. Spore print was observed as rosy or pink in color [Figure 1C]. $V$. bombycina spores were elliptical, smooth, Cystidia long; variously shaped. Pileipell is 
without gelatinized hyphae. Clamp connection was not seen (Figure 1D)

\section{Pure culture of mycelium and spawn preparation}

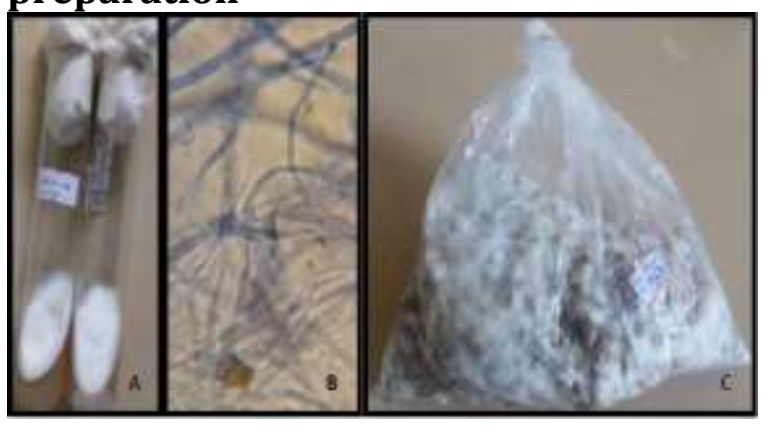

Figure 2: $V$. bombycina A. pure culture of mycelium B. Microscopic view [100X] and C. Mother spawn.

White mycelia were isolated on the PDA tubes. Septate mycelium was observed under microscopic view (Figure 2 A \& B]. The mother culture of the mycelium of $V$. bombycina was initiated after 4-5 days of incubation. The pure culture of the mycelium was isolated by repeated sub culturing on PDA tubes. Incubation period varies between 15-20 days depending upon density of mycelium.

The spawn was developed in wheat grains. The mycelium was fully colonized in wheat grains after incubation of 2-3 weeks (Figure 2 C).

\section{Fruiting bodies development}

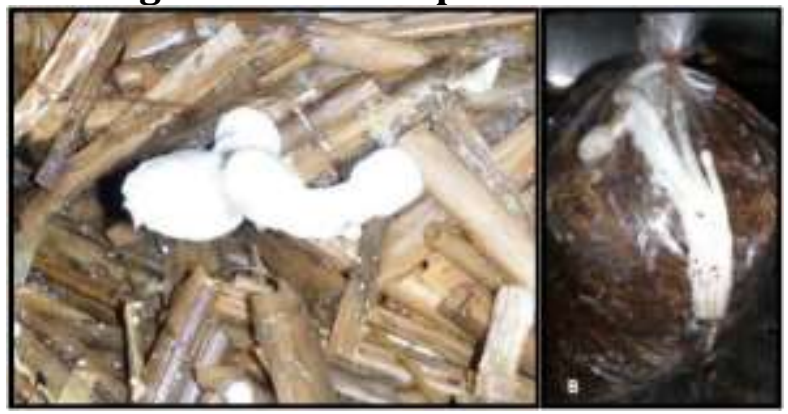

Figure 3: Cultivated fruiting bodies A. early stage B. mature stage.

Mycelium colonization was observed in substrates after one week of incubation. Primordial was initiated during 10-15 days of incubation. Button stage and mature fruiting bodies were observed during 15-20 days and 2030 days respectively (Figure 3 )

\section{Discussion}

The Genus Volvariella, is easily recognized with pink lamellae and rosy or pink in color spores in Figure $1 \mathrm{D}$.

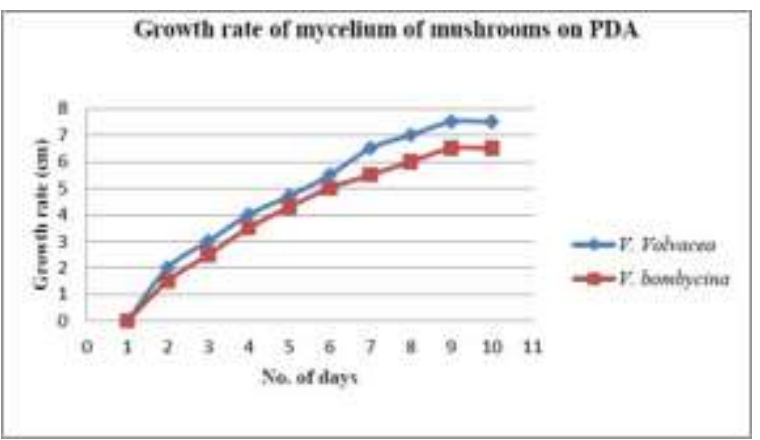

Figure 4: Showing growth curve of mycelium of $V$. volvacea and $V$. bombycina at $25^{\circ} \mathrm{C}$

The stipe of the fruiting bodies doesn't have an annulus. It has volva at the base of the stipe. The lamellae of Volvariellla species are whitish at first, which later becomes pink [6]. Growth rate of mycelium of $V$. bombycina showed slower in contrast to $V$. volcacea (Figure 4). According to Jonathan \& Awotona in 2011, mycelia of $V$. bombycina showed best growth at $28^{\circ} \mathrm{C}$ and $\mathrm{pH}$ 6.8 [21].

It has been reported that straw alone is not sufficient as a composting material as it contains a little quantity nutrients and has a slow rate of decomposition [25]. The cultivation of wild edible mushroom $V$. bombycina was grown by using local agricultural waste substrate, paddy straw supplemented with saw dust and rice husk. Formulation of mushroom substrates presents a very essential factor for the multiplication of mycelium, as it allows the penetration of the mycelium, which influences the fruiting of mushroom. Mushroom produces various enzymes which makes it capable of utilizing the complex lignocellulosic organic compounds [22]. It took 1-2 weeks for complete mycelial colonization in the substrates. Incubation allows the colonization of mycelium in the substrate of the paddy straw mushroom, mycelium of $V$. bombycina grows at slightly low temperature $\left[25^{\circ} \mathrm{C}-30^{\circ}\right.$ C] compared to $V$. volvacea and requires relative humidity $80-90 \%$. A variety of waste materials have been used for cultivation of Volvariella mushroom that include paddy straw, water hyacinth, oil palm bunch and oil palm pericarp waste, banana waste, sawdust, cotton waste, sugar cane bagasse, composted mixtures of tropical wood wastes and pineapple skin waste. These substrates provide essential macro elements for crop 
production [potassium, calcium, phosphorous, magnesium, nitrogen and sodium] [20].

The formation of fruiting primordial or initials requires minimal ventilation and light penetration to stimulate the synchronized fruiting. Formation of fruiting primordial is one of the most critical stage which depend upon physical factors viz. temperature, ventilation and light [23]. The transition from the vegetative hyphae to the formation of primordial and the subsequent development of fruiting bodies depends on many factors, genetic as well as environmental. Environmental factors can affect the yield the yield, timing of fruition and other characteristics of the crop depending upon its genetic potential [20]. Consequences between environmental factor and mushroom growth substrates have been reported to play an important role in inducing the formation of fruiting bodies [24].

\section{Conclusion}

Hence, in vitro cultivation procedure for Volvariella bombycina under laboratory conditions was optimized. The optimized protocol can be utilized for commercial scale cultivation with further processing and optimization.

\section{Author's Contribution}

PKC, BHP and MKA conceived and designed the experiments; PKC performed the experiments; PKC and MS analyzed the data; PKC wrote the paper; MS revised and proof read the manuscript. All authors have read and approved the final version of the manuscript.

\section{Conflict of Interests}

The authors declare no competing interests for publication of this paper.

\section{Ethical issues}

As the research involved no human or animal specimens, ethical approval for conducting this research work was not necessitated.

\section{Acknowledgement}

The authors are grateful to Central Department of Biotechnology, Tribhuvan University for supplementing the required laboratory services, materials and reagents. The authors would also like to thank Prof. Rajani Malla, and Prof. Krishna Das Manandhar for their helpful insights.

\section{References}

1. Boa ER: Wild edible fungi: a global overview of their use and importance to people. Food \& Agriculture Org; 2004.

2. Adhikari MK: Mushrooms of Nepal. Second edition. K.S. Adhikari; 2014.

3. Chiu SW, Moore D, Chang ST: Basidiome polymorphism in Volvariella bombycina. Mycol Res British Mycological Society. 1989 92[1]:69-77.

4. Shaffer RL: Volvariella in North America. Mycologia. 1957 49[4]:545.

5. Lakhanpal TN, Kumar A, Kaisth K: Fleshy fungi of North-Western Himalaya-I. A temperate white from of Volvariella bombycina. Indian J Mushrooms. 1986 12:1-4.

6. Adhikari MK: Volvariella bombycina: A Mycofloral Species from Nepal. J Plant Resour. 2017, 15[1]:1-3.

7. Sabir SM, Hayat I, Hussain I, Gardezi SRA: Proximate Analysis of Mushrooms of Azad Kashmir. Plant Pathol J 2003 2[2]:97-101.

8. Seok SJ, Kim YS, Weon HY, Lee KH, Park KM, Min KH: Taxonomic Study on Volvariella in Korea. Mycobiology 2002 Dec 1, 30[4]:183.

9. Zoberi MH. Introduction. In: Tropical Macrofungi: some common species. London: Palgrave Macmillan UK, 1972

10. Dickinson $\mathrm{CH}$, Lucas JA: The encyclopedia of mushrooms. Orbis, 1979.

11. Fischer D, Bessette A: Edible wild mushrooms of North America: a field-to-kitchen guide. University of Texas Press, 2010.

12. Huang $\mathrm{N}, \mathrm{Wu} \mathrm{S}$ : A preliminary study on the silver-silk straw mushroom, Volvariella bombycina [Pers. ex Fr.] Sing. Mushroom Newsl Trop. 1982 3:6-9.

13. Elliott $T$, Challen M: The breeding system of the silver-silk straw mushroom, Volvariella bombycina. Mushroom Newsl Trop. 1985 6:3-8.

14. Chiu SW, Chen M, Chang S-T: Differentiating homothallic Volvariella mushrooms by RFLPs and AP-PCR. Mycol Res. 1995 99[3]:333-6, doi: 10.1016/S0953-7562[09]80909-X, .

15. Xu G-H, Choo S-J, Kim Y-H, Ryoo I-J, Seok S-J, Ahn J-S: Secondary metabolites of Volvariella bombycina and their inhibitory effects on melanogenesis. J Microbiol Biotechnol. 2010 20[1]:78-81. 
16. Xu G-H, Kim Y-H, Choo S-J, Ryoo I-J, Zheng CJ, Seok S-J: Isodeoxyhelicobasidin, a novel human neutrophil elastase inhibitor from the culture broth of Volvariella bombycina. J Antibiot. 2009 62[6] :333-4, doi: /10.1038/ja. 2009.24

17. Badalyan S: Edible and medicinal higher basidiomycetes mushrooms as a source of natural antioxidants. Int J Med Mushrooms. 2003 5[2], doi: 10.1615/InterJMedicMush.v5.i2.40.

18. Schillaci D, Arizza V, Gargano ML, Venturella G: Antibacterial Activity of Mediterranean Oyster Mushrooms, Species of Genus Pleurotus [Higher Basidiomycetes]. Int J Med Mushrooms. 2013 15[6]:591-4, doi:10.1615/IntJMedMushr.v15.i6.70.

19. MuthusamyKaran, Tamilkani $P$, Senthilkumar G, Vijayalakshmi S, Panneerselvam A: Volvariella bombycina of Tamil Nadu. Int J Inf Res Rev. 2016 3[4]:2175-8.

20. Chang S, Miles P. Mushrooms: cultivation, nutritional value, medicinal effect and environmental impact CRC Press. New York. 2004.

21. Jonathan SG, Awotona FE: Effect of different physico-chemical factors and agricultural wastes on mycelia growth and fruit bodies production of Volvariella bombycina [Schaeff: Ex.Fr] Singer. An Indian J. 2011 3[4]:3-6.

22. Mane VP, Patil SS, Syed AA, Baig MMV: Bioconversion of low quality lignocellulosic agricultural waste into edible protein by Pleurotus sajor-caju [Fr.] Singer. J Zhejiang Univ Sci B 2007 8[10]:745-51. doi: 10.1631/jzus. 2007.B0745.

23. Reyes RG: Indoor cultivation of paddy straw mushroom, Volvariella volvacea, in crates. Mycologist 2000 14[4]:174-6.doi: 10.1016/S0269915X[00]80037-3.

24. Reyes RG, Lou L, Lopez M a, Kumakura K, Kalaw SP: Coprinus comatus, a newly domesticated wild nutriceutical mushroom in the Philippines. J Agric Technol 2009 5[2]:299316.

25. Anon: Growing mushrooms: Cultivation of Volvariella volvacea. 1983, 56-63. 